\title{
Mechanical behaviour of polymeric foam core at various orientation angles
}

\author{
M. R. M. Rejab ${ }^{1}$, M. S. M. Sani ${ }^{1}$, M. M. Noor ${ }^{1}$, K. Kadirgama ${ }^{1}$, \\ M. M. Rahman ${ }^{1}$ \& A. Alias ${ }^{2}$ \\ ${ }^{1}$ Universiti Malaysia Pahang, Pahang, Malaysia \\ ${ }^{2}$ Universiti Teknologi Malaysia, Johor, Malaysia
}

\begin{abstract}
Polymeric foam is widely used as core materials in various applications such as cushioning, padding, insulating, structural use and buoyancy. This is because of its ability to provide high bending stiffness tied with lightweight in composite sandwich construction. The purpose of this paper is to present the behaviour of polyurethane foam, which is fabricated in various orientation angles. Five different orientation angles have been studied i.e. $0^{\circ}, 30^{\circ}, 45^{\circ}, 60^{\circ}$ and $90^{\circ}$. Three mechanical tests were performed under tension, compression and shear loads to investigate the polyurethane foam (PU) behaviour. Electron microscope was used to capture the microstructure of the specimens before and after the tests. Comparisons have been made between different orientation angles in fracture modes and mechanical properties. Deformation and failure occur during foam crushing are discussed according to experimental evidence. Since the main application of foam materials are for energy absorption, foam response under considerable compression has been studied intensively. At angle of $90^{\circ}$, it permits more localised failure with high-energy absorption and in contrary, $0^{\circ}$ which posses the lowest of energy absorption. Energy absorption for PU foam material tends to increase when the orientation of angle is increased.

Keywords: polyurethane foam, cell orientation angles, fracture mode.
\end{abstract}

\section{Introduction}

Foam materials have a cellular structure with a three-dimensional array of cells and they are being used increasingly in engineering. Their microscopic cellular structure determines their superior performance as an energy absorbing materials 
and as a core material in sandwich panels. However, their mechanical behaviours are complex due to their cellular structure. More materials tests are required to determine their mechanical properties for structural design and numerical simulation purposes. Currently, the standard tests on mechanical properties of foam core materials include uniaxial tension test (ASTM C297), uniaxial compressive (ASTM D365) and shear (ASTM C273) tests.

In order to understand the mechanical behaviours of foam materials in the general loading case, experimental and theoretical studies have been conducted for a variety of loading paths. Yield and failure surface of various foams have been presented based on experimental results and constitutive models [1-3]. Microscopic mechanics of cellular materials were introduced by Ashby and Gibson (1997) to relate microscopic behaviour to cell-wall properties and geometric constructions of the foam [4]. The most common foam materials used in all applications except aerospace are polyurethane, polystyrenes, polyvinyl chlorides and polyphenolics, which are a group of expanded polymeric foams. Recently, rigid polyurethane foam is becoming a well-known foam core material because of its meritorious properties [5, 6]. This rigid polyurethane (PUR) foam is used as a sample for this research.

The aims of this study are to obtain the effect of foam properties in various orientations and its behaviour in an energy absorption point of view. Reliable techniques of manufacturing this foam core were used and the experimental data have been analysed to determine their mechanical properties for structural design and numerical simulation purposes

\section{Material preparation}

In this study, PUR foam was used as the specimen. Two chemical components are used to fabricate the foam. Component $\mathrm{A}$ is called polyol blend (RF 0597/3A) and component B is called isocyanate (RF0597/3B). The chemicals were supplied by Asia Polyurethane Manufacturing (APM), Singapore. The foam was manufactured to get slab stock foam by using an injection foaming process in a special in-situ mould [7]. The PUR chemicals used were based on a ratio of $50 \%$ of component $\mathrm{A}$ and component $\mathrm{B}$, respectively. This ratio was chosen because the ratio gave a uniform and consistent microstructure for this structural foam. The samples were prepared from slab stock foam into cubes with dimensions of $25 \mathrm{~mm} \times 25 \mathrm{~mm} \times 25 \mathrm{~mm}$ as shown in Figure 1 . The foam weight was determined by using electronic weighing scales. The density of foam $\rho$ was measured according to standard ASTM D1622-98.
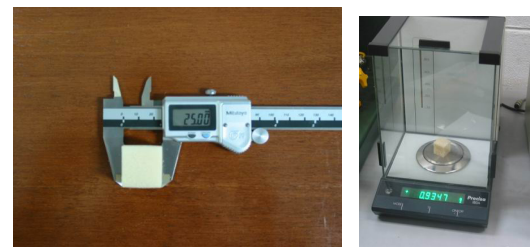

Figure 1: $\quad$ Specimen dimension and measuring of foam weight. 
Table 1 shows the density of the measured PUR. Based on the table, the average apparent density of the PUR foam was $64.01 \pm 0.2 \mathrm{~kg} / \mathrm{m}^{3}$.

Table 1: Density of the measured PUR foam.

\begin{tabular}{ccccccc}
\hline $\begin{array}{c}\text { Sample } \\
\left({ }^{\circ}\right)\end{array}$ & $\begin{array}{c}\text { Weight } \\
(\mathrm{g})\end{array}$ & $\begin{array}{c}\text { Height } \\
(\mathrm{mm})\end{array}$ & $\begin{array}{c}\text { Length } \\
(\mathrm{mm})\end{array}$ & $\begin{array}{c}\text { Width } \\
(\mathrm{mm})\end{array}$ & $\begin{array}{c}\text { Volume } \\
\left(\mathrm{mm}^{3}\right) \times 10^{3}\end{array}$ & $\begin{array}{c}\text { Density, } \\
p\left(\mathrm{~kg} / \mathrm{m}^{3}\right)\end{array}$ \\
\hline 0 & 1.0056 & 25.09 & 24.91 & 25.11 & 15.69 & 64.07 \\
30 & 1.0094 & 25.04 & 25.12 & 25.04 & 15.75 & 64.09 \\
45 & 1.0135 & 25.13 & 25.10 & 25.12 & 15.84 & 63.96 \\
60 & 1.0084 & 25.14 & 25.05 & 25.09 & 15.80 & 63.82 \\
90 & 1.0117 & 25.06 & 25.11 & 25.07 & 15.78 & 64.13 \\
\hline & & & & Ave: & 64.01 \\
\hline
\end{tabular}

\section{Experimental work}

In this study, three types of tests have been considered and experimental tests were performed to collect the appropriate data for this PUR foam.

\subsection{Compression test}

A compression test was conducted in an INSTRON 100kN series 4206 testing machine according to standards ASTM D1621-1987. The specimens were 25mm thick, and the other dimensions were the same, $25 \mathrm{~mm}$ by $25 \mathrm{~mm}$. As shown in Figure 2, the specimen was placed between the platens of the machine and was deformed at a quasi-static loading rate $1 \mathrm{~mm}$ per minute, which gives an engineering strain rate of $6.7 \times 10^{-4} \mathrm{~s}^{-1}$.

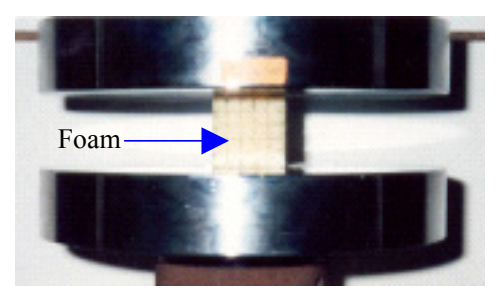

Figure 2: Compression test setup.

\subsection{Tension test}

The foam tension test was conducted on an INSTRON $100 \mathrm{kN}$ series 4206 testing machine to the relevant standard ASTM C297-1961. The specimens were $25 \mathrm{~mm}$ thick and the other dimensions were $25 \mathrm{~mm}$ by $25 \mathrm{~mm}$. The blocks of the foam were bonded to aluminium blocks using Araldite glue. The curing time was 3 hours at $40^{\circ} \mathrm{C}$. The testing rig is designed to allow for both forward and lateral 
deflections which eliminate the bending effect (Figure 3). The stiffness of the testing machine was compensated for by replacing the foam with an aluminium block. The crosshead speed was $1 \mathrm{~mm}$ per minute, which gives an engineering strain rate of $6.7 \times 10^{-4} \mathrm{~s}^{-1}$.

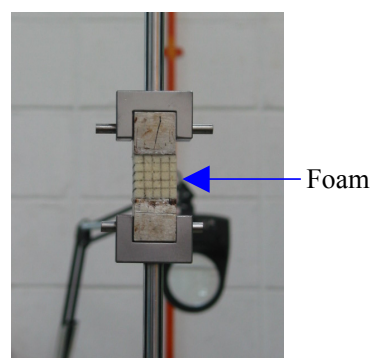

Figure 3: Tension test setup.

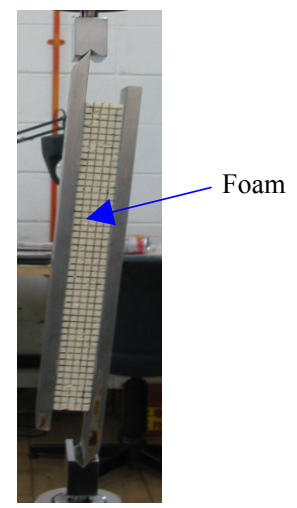

Figure 4: $\quad$ Shear test setup.

\subsection{Shear test}

The foam shear test is defined in ASTM standard C273-1961. There are two versions of the test, namely, tensile and compression loading. The compression version was used. The specimen geometry was $25 \mathrm{~mm}$ thick with the other dimensions being $240 \mathrm{~mm}$ by $50 \mathrm{~mm}$. It was then tested on the INSTRON $100 \mathrm{kN}$ series 4206 testing machine.

The load line should act through the opposite corners of the foam specimen. The foam was bonded to the platens using Araldite glue (Figure 4). The bonding between rigid and the foam was important because, if not, failure would occur at the bonding of the foam and the platen and the shear data would not be accurate. 


\section{Results and discussions}

In this study, three types of tests have been considered and experimental tests were performed to collect the appropriate data for this PUR foam.

Figure 5 shows the compression test of foam that was performed to ascertain the mechanical behaviours. This is to determine the energy absorption and maximum compression strength for every sample. Based on the graph, the PUR $90^{\circ}$ sample gives the largest value of core compression modulus which is $1.65 \mathrm{MPa}$, whereas the maximum compression stress is $0.159 \mathrm{MPa}$ with 0.09 of strain. The lowest core compression modulus is $0.627 \mathrm{Mpa}$, that is, for the orientation of $0^{\circ}$ with a maximum compression stress value at $0.10 \mathrm{MPa}$. Other samples including 30,45 and $60^{\circ}$ indicate a core compressive strength of $0.068 \mathrm{MPa}, 0.074 \mathrm{MPa}$ and $0.125 \mathrm{MPa}$ with the amount of strain valued at 0.099 , 0.93 and 0.98 , respectively.

Figure 6 shows the compression yield stress of PUR foam in various orientations. From the figure, it is clearly shown that the value of compression

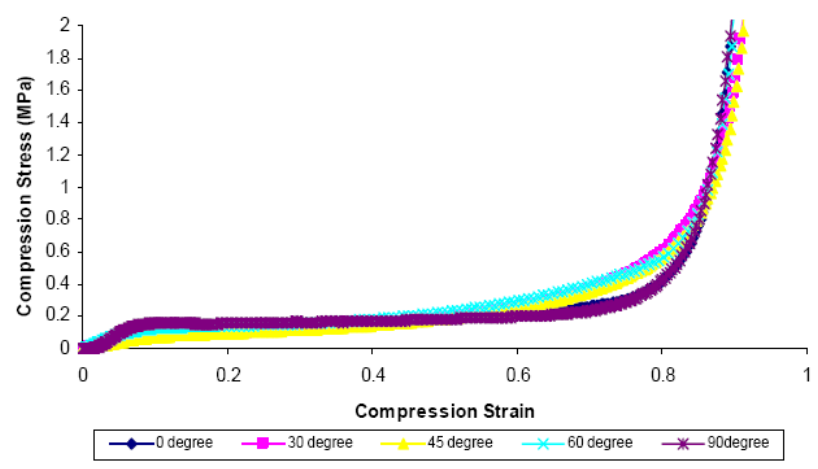

Figure 5: Compression stress-strain curves for five different orientation angles.

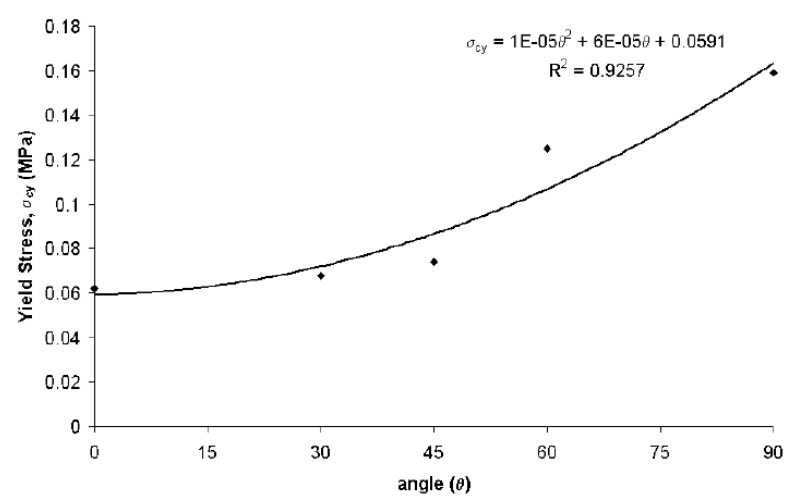

Figure 6: Compression yield stress at various orientation angles. 
yield stress increases with the increase of the PUR foam angle in the polynomial relation. A minor increment occurred in the range of $0^{\circ}$ and $45^{\circ}$. The increment of yield stress value is about $0.06 \mathrm{MPa}$ or about $9 \%$.

A sudden rise is noticed in the values of the yield stress. This occurred between the range of $45^{\circ}$ and $60^{\circ}$. The value increased by $0.051 \mathrm{MPa}$ or $68 \%$. The highest and lowest value of yield stress is about $0.159 \mathrm{MPa}$ and $0.062 \mathrm{MPa}$ which happened for $90^{\circ}$ and $0^{\circ}$ respectively. Equation (1) is derived in the graph as shown below:

$$
\sigma_{c y}=1^{-05} \theta^{2}+6^{-05} \theta+0.0591(\mathrm{MPa}), 0^{\circ}<\theta<90^{\circ}
$$

Figure 7 shows the tensile test of foam that has been performed to ascertain the mechanical behaviours. This is to determine the maximum tension strength for every sample. Based on the above figure, the PUR $90^{\circ}$ sample gives the largest value of core tensile modulus which is $3.53 \mathrm{MPa}$. Whereas the maximum tension stress resulted at $0.323 \mathrm{MPa}$ with 0.09 of strain. The lowest core tension modulus is $0.567 \mathrm{Mpa}$, that is, for the orientation of $30^{\circ}$. Other samples including 0,45 and $60^{\circ}$ indicate a core compressive strength of $0.15 \mathrm{MPa}, 0.176 \mathrm{MPa}$ and $0.202 \mathrm{MPa}$ with the amount of strain valued at $0.21,0.22$ and 0.17 , respectively.

Figure 8 shows the tension yield stress of PUR foam in various orientations. It shows that the value of tension yield stress PUR foam increases with the increase of the PUR foam angle. The graph is a polynomial type of graph. From the lowest angle, the yield stress increases up to $0.323 \mathrm{MPa}$ to fail at the highest angle of the PUR foam specimen $\left(90^{\circ}\right)$. The graph shows a uniform increment in the angle range of $0^{\circ}$ and $60^{\circ}$ with $14 \%$ of increment. The value of yield stress increased rapidly in the angle range of $60^{\circ}$ and $90^{\circ}$. The increase of yield stress value is $0.121 \mathrm{MPa}$ or in a percentage is $60 \%$ before failing. While the difference between the highest and lowest value is $0.188 \mathrm{MPa}$ for $90^{\circ}$ and $0^{\circ}$. Equation (2) is derived from the graph as shown below:

$$
\sigma_{t f}=3^{-05} \theta^{2}-0.0005 \theta+0.1363(\mathrm{MPa}), 0^{\circ}<\theta<90^{\circ}
$$

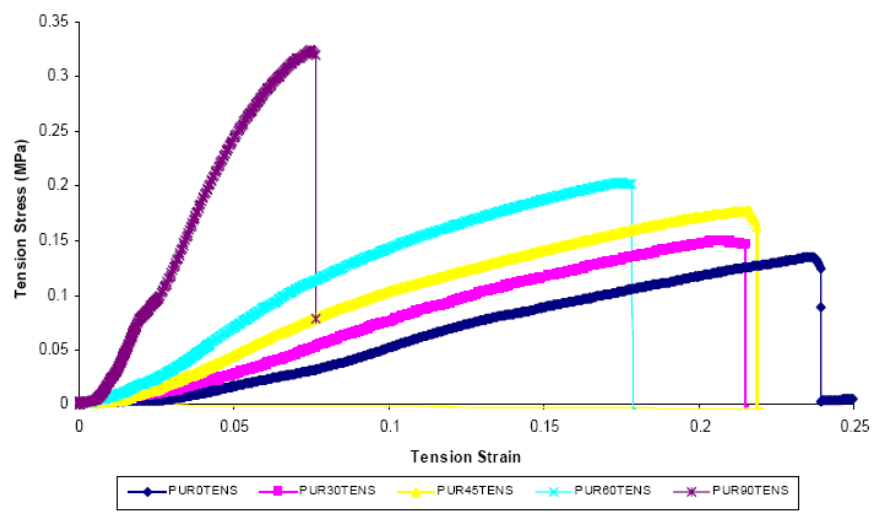

Figure 7: Tension stress-strain curves for five different orientation angles. 


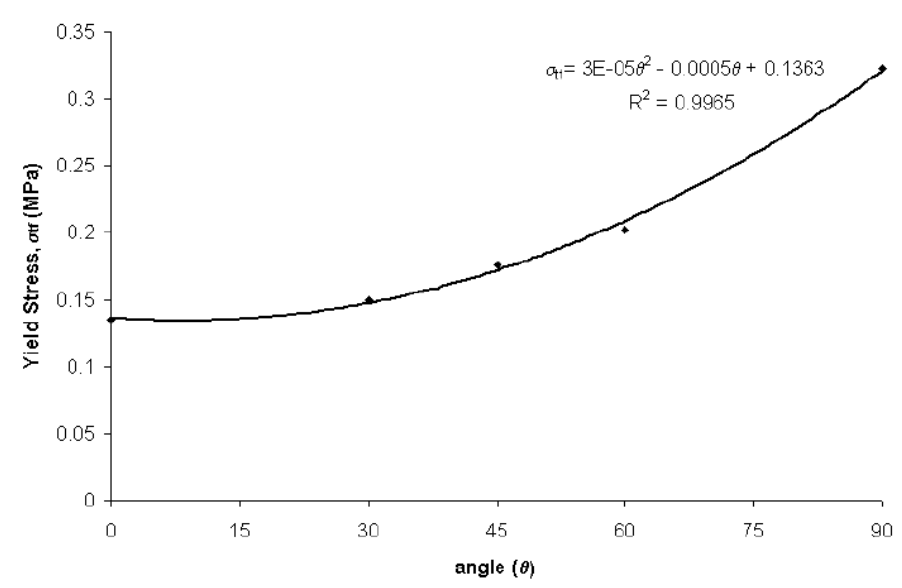

Figure 8: $\quad$ Tension yield stress at various orientation angles.

Figure 9 shows the shear test of foam which has been performed to ascertain the mechanical foam behaviours, widely used as a core for the sandwich structure. These mechanical behaviours should be known to determine the maximum shear strength for each sample. Based on the above graph, the PUR $90^{\circ}$ sample gives the largest value of core shear modulus, that is, $1.32 \mathrm{MPa}$. This is because most of the direction force which has been loaded is absorbed by the $90^{\circ}$ cell of structure foam. The maximum shear is $0.123 \mathrm{MPa}$ with 0.031 of strain. Whereas the lowest cores shear modulus is $0.95 \mathrm{MPa}$ which occurred during the orientation of $0^{\circ}$. This is because the forces applied could not be borne by the cell structure. Whereas the cores shear modulus for the sample 30, 45 and $60^{\circ}$ are $1.07 \mathrm{MPa}, 1.16 \mathrm{MPa}$ and $1.98 \mathrm{MPa}$ accordingly with the core shear strength of $0.110 \mathrm{MPa}, 0.114 \mathrm{MPa}$ and $0.121 \mathrm{MPa}$, respectively.

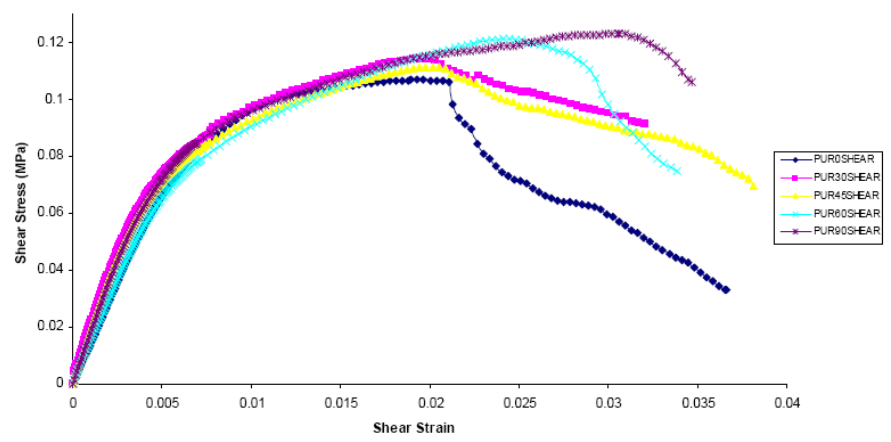

Figure 9: $\quad$ Shear stress-strain curves for five different orientation angles. 
Figure 10 shows the shear yield stress of PUR foam in various orientations. It shows that the value of shear yield stress increases with the increase of PUR foam angle in a linear relation. From the lowest angle, the yield stress increase up to $0.106 \mathrm{MPa}$ before failure occurred at the highest angle of PUR foam specimen with $0.123 \mathrm{MPa}$.

The value of yield stress increased rapidly in the angle range of $45^{\circ}$ and $60^{\circ}$. The increase of yield stress value is $0.007 \mathrm{MPa}$ or, in a percentage, is $6 \%$ before failing, while the difference between the highest and lowest value is $0.017 \mathrm{MPa}$ for $90^{\circ}$ and $0^{\circ}$. Equation (3) is derived from the graph as shown below:

$$
\tau_{f}=0.0002 \theta+0.1055(\mathrm{MPa}), 0^{\circ}<\theta<90^{\circ}
$$

The PUR foam that has undergone a compression test had been analysed using Stereo Microscope with magnification 10X and 20X. The microstructures of closed cell of PUR are shown as in Figure 11. The microscopic structure of the sample was taken using a stereo microscope with a calibration of $0.31646 \mu \mathrm{m} /$ Pixel (magnification 20X).

Figure 11 shows that the plateau range of crushable foam in compression, caused by cell-wall collapse. The cell-wall for all samples had collapsed in compression which could be one of cell-wall buckling, cell wall breaking and the formation of foam hinges in the cell wall, or a combination of them. From the microstructure analysis, the characteristic cell-wall size and cell wall thickness is decreased. The average of the cell-wall size was moved between $10 \mu \mathrm{m}$ and $15 \mu \mathrm{m}$ and the cell-wall thickness was still between $1 \mu \mathrm{m}$ to $10 \mu \mathrm{m}$. It also shows that the crash of diameter of the cell, respectively, is equal.

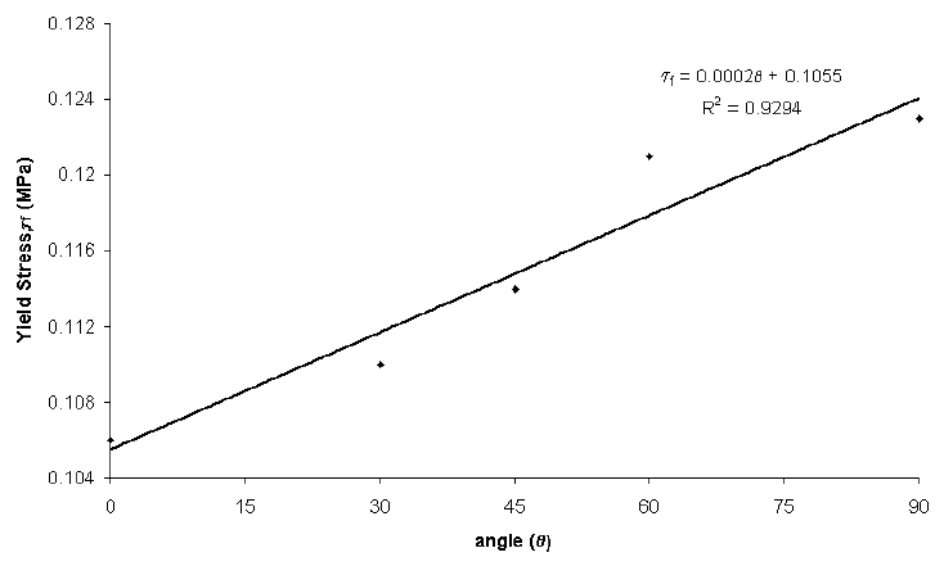

Figure 10: Shear yield stress at various orientation angles. 


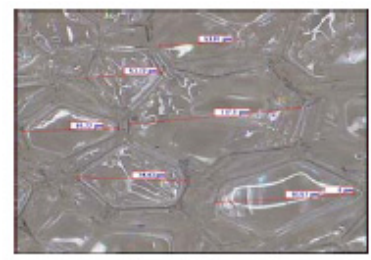

Before (0 degree)

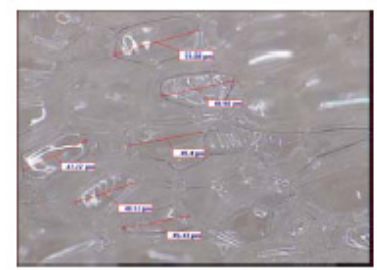

Before (30 degree)

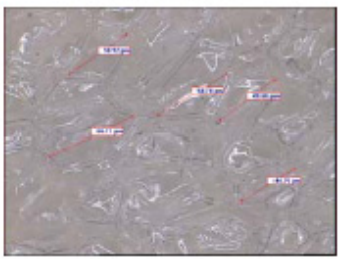

Before (45 degree)

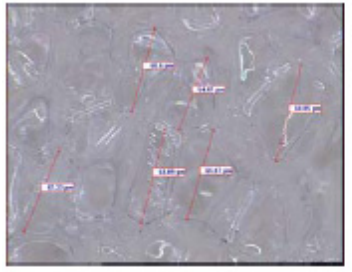

Before (60 degree)

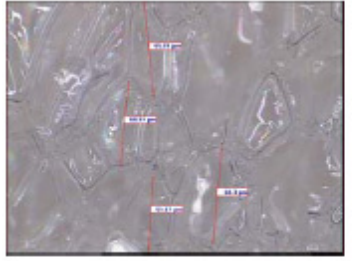

Before (90 dearee)

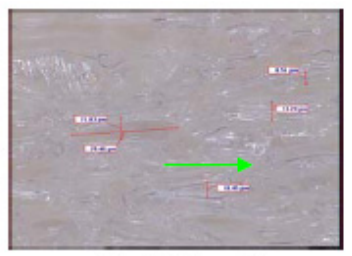

After ( 0 deqree)

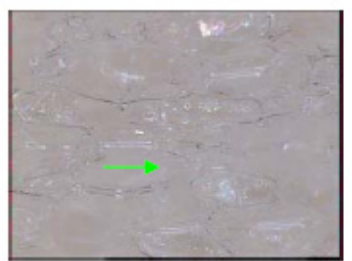

After (30 degree)

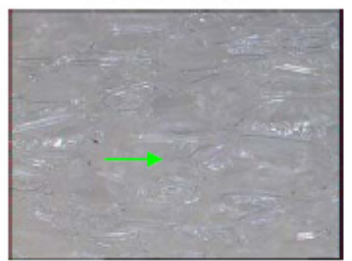

After ( 45 degree)

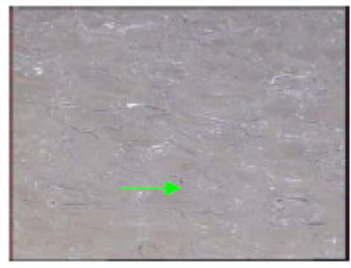

After (60 dearee)

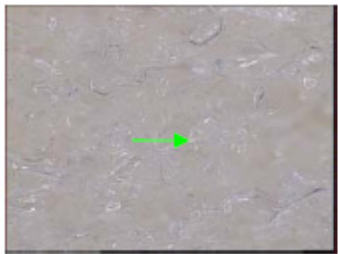

After ( 90 dearee)
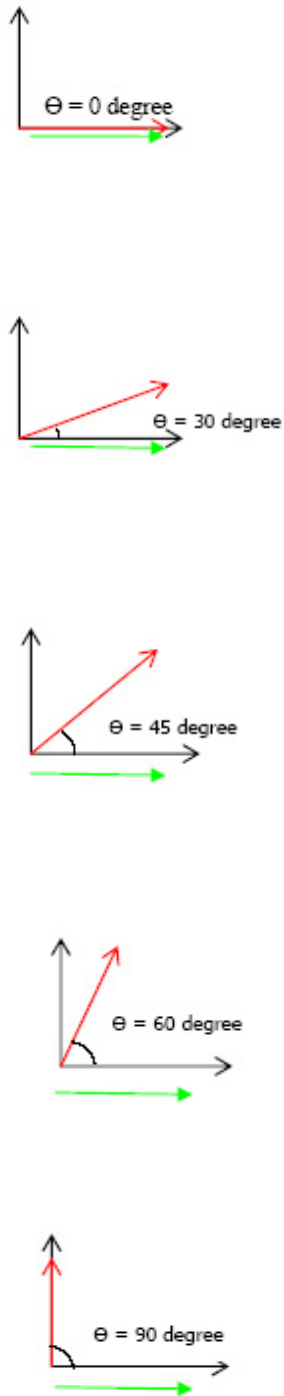

Figure 11: Shear yield stress at various orientation angles.

\section{Conclusion}

In conclusion, the purpose of this project is to study the effect of orientation of the fabrication of foam core under several mechanical tests, such as compression, 
tension and shear tests. In this study, several mechanical behaviours of PUR foam which relate to orientation have been determined. From the analyses that have been done to the foam structure, it can be concluded that the PU foam is good at bearing the compression load and also has a good absorbing value. The PUR foam under compression test has been studied intensively to determine the energy absorption for each type of condition. For $90^{\circ}$, it permits more localised failure with high energy absorption, unlike $0^{\circ}$ which possesses the lowest of energy absorption. Energy absorption for PUR foam material tends to increase when the orientation of angle is increased. Therefore, the higher foam angle orientation gives higher stiffness and energy absorption.

\section{Acknowledgement}

The financial support by Universiti Malaysia Pahang is grateful acknowledged.

\section{References}

[1] Avalle, M., Belingardi, G. and Montanini, R., Characterization of polymeric structural foams under compressive impact loading by means of energyabsorption diagram. International Journal of Impact Engineering, 25, pp. 455-472, (2001).

[2] Li, Q.M., Mines, R.A.W. and Birch, R.S., The crush behaviour of Rohacell$51 \mathrm{WF}$ structural foam. International Journal of Solids and Structures, 37, pp. $6321-6341,2000$.

[3] Triantafillou, T.C., Zhang, J., Shercliff, T.L., Gibson, J.L. and Ashby, M.F., Failure surface for cellular materials under multiaxial loading-II Comparison of model with experimental. International Journal of Mechanical Science, 31, pp. $665-678,1989$.

[4] Gibson, J.L. and Ashby, M.F., Cellular Solids. Cambridge University Press, 1997.

[5] Alias, A. and Mines, R.A.W., Experimental results and techniques on the crush behaviour of structural foam. Proc. of the $3^{\text {rd }}$ International Symposium on Impact Engineering, Singapore, pp. 379 - 384, 1998.

[6] Mines, R.A.W., Li, Q.M., Alias, A,. Birch, R.S. and Close, J.A., On the measurement of the crush behaviour of structural foams. Proc of the 11th International Conference on Experimental Mechanics, Oxford, 1998.

[7] Rejab, M.R.M., Alias, A. and Ismail, Y.S. In-situ technique in manufacturing structural sandwich beams. Proc. of Research Seminar on Materials and Constructions, UTM Skudai, October 2002. 